\title{
SPR28, a sixth member of the septin gene family in Saccharomyces cerevisiae that is expressed specifically in sporulating cells
}

\author{
Claudio De Virgilio, $†$ Douglas J. DeMarini and John R. Pringle \\ Author for correspondence: John R. Pringle. Tel: +1 919962 2293. Fax: +19199620320. \\ e-mail: jpringle@email.unc.edu
}

Department of Biology, University of North Carolina, Chapel Hill, NC 27599, USA

\begin{abstract}
The septins are a recently recognized family of proteins that are present in a wide variety of fungal and animal cells, where they are involved in cytokinesis and apparently in other processes involving the organization of the cell surface. Five previously described Saccharomyces cerevisiae septins are associated with the neck filaments of vegetative cells and/or with the developing prospore wall of sporulating cells. We report here the characterization of SPR28, a sixth member of the S. cerevisiae septin gene family whose existence was revealed by the yeast genome project. Analysis of mRNA levels showed that SPR28 is a new member of the group of 'late genes' that are expressed at high levels during the meiotic divisions and ascospore formation. The septin it encodes, Spr28p, exhibited specific two-hybrid interactions with itself and with three other septins that are expressed in sporulating cells. Consistent with these results, an Spr28p-green fluorescent protein fusion was induced during meiosis I and appeared to be associated with the developing prospore walls. Deletion of SPR28 in either a wild-type or an spr $3 \Delta$ background produced no obvious abnormalities in vegetative cells and had little or no effect on sporulation, suggesting that the septins have redundant roles during spore formation.
\end{abstract}

Keywords: septins, SPR28, Saccharomyces cerevisiae, sporulation, cell wall synthesis

\section{INTRODUCTION}

Sporulation of the yeast Saccharomyces cerevisiae involves a regulated programme of cell development that includes pre-meiotic DNA replication, the two meiotic divisions, and encapsulation of the haploid nuclei within the spore walls (Esposito \& Klapholz, 1981). Sporulation is initiated when $M A T \mathbf{a} / M A T \alpha$ cells are starved for nitrogen in the presence of a nonfermentable carbon source and is under the control of master regulatory genes that include IME1, IME2 and RME1 (reviewed by Mitchell, 1994). To help produce the proper sequence of genetic and morphological events during sporulation, three classes of sporulation-specific genes are activated at distinct times during the process (Mitchell, 1994): early genes are expressed at the beginning of meiotic prophase, middle

\footnotetext{
†Present address: Botanisches Institut der Universităt Basel, $\mathrm{CH}-4056$ Basel, Switzerland.

Abbreviations: $A D$, activation domain; DBD, DNA-binding domain; GFP, green fluorescent protein.
}

genes are expressed later in prophase, and late genes are expressed at the time of the meiotic divisions and spore formation. Activation of the late genes is accompanied and followed by the morphological events of spore formation, which include (i) formation of a flattened membrane sac (the 'prospore wall') in close apposition to the cytoplasmic faces of the spindle-pole bodies early in meiosis II; (ii) extension of the prospore walls along the outer surface of the nuclear envelope; (iii) separation of the prospore walls from the spindle-pole bodies and the nuclear envelope, and movement of cytoplasm and organelles into the intervening space; (iv) final engulfment of the nuclear lobes (containing the haploid chromosome sets) and associated cytoplasm; and (v) deposition of spore-wall components between the two membranes of the prospore wall (Moens, 1971; Moens \& Rapport, 1971; Guth et al., 1972; Beckett et al., 1973; Byers, 1981).

Among the genes expressed differentially late in sporulation are CDC10 (Kaback \& Feldberg, 1985) and SPR3 (Holaway et al., 1987; Kao et al., 1989; Ozsarac et al., 
1995; Fares et al., 1996), which encode proteins of the septin family. Septins were originally identified in $S$. cerevisiae as a set of homologous proteins (encoded by $C D C 3, C D C 10, C D C 11$ and $C D C 12$ ) associated with the $\sim 10 \mathrm{~nm}$ filaments that lie immediately subjacent to the plasma membrane in the region of the mother-bud neck (Byers \& Goetsch, 1976; Byers, 1981; Haarer \& Pringle, 1987; Ford \& Pringle, 1991; Kim et al., 1991 ; Longtine et al., 1996). In temperature-sensitive mutants defective in any of these four septins, a shift to restrictive temperature results in a pleiotropic phenotype that includes loss of the neck filaments, failure to form a chitin ring in the cell wall at the base of the bud, production of abnormally elongated buds, and a failure to complete cytokinesis, resulting in the formation of multibudded, multinucleate cells (Hartwell, 1971; Byers, 1981; Adams, 1984; Adams \& Pringle, 1984; Slater et al., 1985; D. DeMarini, A. E. M. Adams and J. R. Pringle, unpublished results). Recent work has shown that septins are also present in a variety of other organisms, including other fungi, insects, amphibia and mammals (reviewed by Longtine et al., 1996). The septins appear to be generally involved in cytokinesis and/or septum formation, and protein-localization data suggest that they may also have a variety of other roles (Longtine et al., 1996).

In $S$. cerevisiae, immunofluorescence analysis of the sporulation-specific septin Spr3p, and of Cdc3p and Cdc11p (which are expressed in both vegetatively growing and sporulating cells), suggested that these proteins are all localized to the prospore walls throughout the development of this structure (Fares et al., 1996). These results, together with the finding that deletion of SPR3 or of $C D C 10$ reduced the efficiency of sporulation, suggest that the septins might play an important role during the formation of the prospore wall and/or in the eventual formation of the spore wall within it.

In this study, we report the analysis of a sixth $S$, cerevisiae septin gene, SPR28 (SPorulation-Regulated), whose existence was revealed during the yeast genome project. Like SPR3, SPR 28 is expressed specifically as one of the late group of sporulation genes, and its product appears to be localized to the prospore wall. Deletion of SPR 28 in a wild-type or an $\operatorname{spr} 3 \Delta$ background did not produce a substantial decrease in sporulation efficiency, suggesting that the septins play partially redundant roles during spore formation.

\section{METHODS}

Strains, media, and microbiological and recombinant DNA methods. The $S$. cerevisiae strains used in this study are listed in Table 1. Strains CDV46-1 to CDV46-6 and CDV47-1 to CDV47-6 were constructed by crossing haploid segregants from five different tetrads from CDV45 as follows: CDV453C $\times$ CDV45-3D (CDV46-1), CDV45-2A $\times$ CDV45-4A (CDV46-2), CDV45-1B $\times$ CDV45-3D (CDV46-3), CDV45$1 \mathrm{D} \times \mathrm{CDV} 45-4 \mathrm{~A} \quad(\mathrm{CDV} 46-4), \quad$ CDV45-2A $\times$ CDV45-3D (CDV46-5), CDV45-4C $\times$ CDV45-5C (CDV46-6), CDV45$1 \mathrm{~A} \times$ CDV45-4B (CDV47-1), CDV45-1 A $\times$ CDV45-3B (CDV47-2), CDV45-1C $\times$ CDV45-3B (CDV47-3), CDV45-
2B $\times$ CDV45-4B (CDV47-4), CDV45-3A $\times$ CDV45-3B (CDV47-5) and CDV45-3B $\times$ CDV45-4D (CDV47-6).

Escherichia coli strain JMB9 $\left[\left(\mathrm{r}^{-} \mathrm{m}^{+}\right) \Delta \operatorname{trpF}\right]$ (Sterner et al., 1995) was used to rescue pJG4-5-based plasmids from strain EGY48. The transformed cells were plated directly onto Vogel-Bonner minimal plates (Davis et al., 1980) that were supplemented with $0.2 \%$ glucose, $0.5 \%$ Casamino acid hydrolysate, $0.01 \mathrm{mM} \mathrm{FeCl}_{3}$ and $100 \mathrm{mg}$ ampicillin $\mathrm{l}^{-1}$. Other plasmid manipulations were performed in E. coli strain DH5 $\alpha$ (Gibco BRL) using standard procedures (Sambrook et al., 1989) except where noted. Standard procedures of yeast genetics and molecular biology (Guthrie \& Fink, 1991 ; Sambrook et al., 1989) were used except where noted. Yeast transformations were performed using a modification of the $\mathrm{Li}^{+}$-ion method (Gietz et al., 1992).

Yeast and E. coli media, including the rich, glucose-containing media YM-P and YPD, the acetate-containing medium YPAc, defined media (SD with appropriate supplements) and sporulation medium, were prepared by standard recipes (Lillie \& Pringle, 1980; Sambrook et al., 1989; Rose et al., 1990). Sporulation experiments were performed essentially as described by Fares et al. (1996) except that all experiments were carried out at $22{ }^{\circ} \mathrm{C}$.

Deletion of SPR28 and construction of an SPR28-GFP fusion. The complete SPR 28 coding region was deleted by the PCR method (Baudin et al., 1993) using plasmid pRS304 (TRP1; Sikorski \& Hieter, 1989) as template and Taq DNA polymerase (Boehringer). Oligonucleotides that contained 40 nucleotides immediately upstream or downstream of the SPR 28 coding region and 20 nucleotides either upstream or downstream of TRP1 were used to create a PCR product that contained flanking sequences of SPR 28 separated by TRP1 and TRP1flanking sequences. This DNA was extracted with phenol/ chloroform $(1: 1, \mathrm{v} / \mathrm{v})$, precipitated and transformed into strain YEF473 (Table 1). A transformant (CDV45) that had one copy of SPR 28 replaced with TRP1 was confirmed by PCR and Southern blot analysis and used to construct other strains as described above.

To construct an SPR28-GFP fusion gene and a GFP gene under control of the SPR 28 promotor, the 446 nucleotides upstream of and including the SPR 28 start codon, with or without the full-length SPR 28 coding region, were amplified by PCR using Vent DNA polymerase (New England Biolabs) and genomic DNA as template. EcoRI and Not I restriction sites were introduced at the ends of each fragment. The two resulting fragments were purified, digested with EcoRI and NotI, and coligated with a Not $\mathrm{I}-B a m \mathrm{HI}$ fragment encoding the green fluorescent protein (GFP; see below) to EcoRI/Bam HI-digested YEplac181 (Gietz \& Sugino, 1988), thus creating YEplac181SPR28-GFP and YEplac181-GFP, respectively. The GFP fragment had been amplified previously by PCR using Vent DNA polymerase and pS65T-C1 (Clontech) as template. NotI and $\mathrm{BamHI}$ restriction sites that allowed in-frame fusions were introduced with the primers.

Two-hybrid analyses. The two-hybrid assay (Fields \& Sternglanz, 1994) was performed as described by Gyuris et al. (1993). To fuse the various full-length septin genes to the LexA DNAbinding domain (DBD) coding sequences in plasmid pEG202 (Zervos et al., 1993) and to the activation domain (AD) coding sequences in a modified version of plasmid pJG4-5 (Gyuris et al., 1993) that contains the polylinker region from pEG202 (C. De Virgilio and D. DeMarini, unpublished results), S, cerevisiae $C D C 3, C D C 10, C D C 11, C D C 12, S P R 3$ and SPR 28 (accession numbers P32457, P25342, P32458, P32468, P41901 and Z48612, respectively) full-length coding sequences were amplified by PCR using Vent DNA polymerase and either cloned genes 
Table 1. S. cerevisiae strains used in this study

\begin{tabular}{|c|c|c|c|}
\hline Strain & & Genotype & Source or reference \\
\hline YEF473 & $a / \alpha$ & bis $3 /$ bis 3 leu $2 /$ leu 2 lys $2 /$ lys $2 \operatorname{trp} 1 / \operatorname{trp} 1$ ura $3 /$ ura 3 & Bi \& Pringle (1996) \\
\hline CDV45 & $a / \alpha$ & $\begin{array}{l}\text { bis } 3 / \text { bis } 3 \text { leu } 2 / \text { leu } 2 \text { lys } 2 / \text { lys } 2 \text { trp } 1 / \operatorname{trp} 1 \text { ura } 3 / \text { ura3 } \\
\text { spr284::TRP1/SPR } 28\end{array}$ & See text \\
\hline CDV45-3A & $\alpha$ & bis 3 leu 2 lys 2 trp1 ura 3 & Segregant from CDV45* \\
\hline CDV45-3B & $\mathbf{a}$ & bis 3 leu 2 lys 2 trp1 ura3 & Segregant from CDV45* \\
\hline CDV45-3C & a & bis 3 leu2 lys 2 trp1 ura 3 spr284:: TRP1 & Segregant from CDV45* \\
\hline CDV45-3D & $\alpha$ & bis 3 leu2 lys 2 trp1 ura 3 spr28 $1:$ TRP1 & Segregant from CDV45* \\
\hline $\begin{array}{l}\text { CDV46-1 to } \\
\text { CDV46-6 }\end{array}$ & $a / \alpha$ & 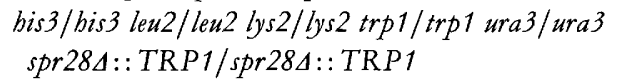 & This study $\dagger$ \\
\hline $\begin{array}{l}\text { CDV47-1 to } \\
\text { CDV47-6 }\end{array}$ & $a / \alpha$ & bis $3 /$ bis 3 leu2/leu2 lys $2 /$ lys $2 \operatorname{trp} 1 / \operatorname{trp} 1$ ura $3 /$ ura 3 & This study $\dagger$ \\
\hline HF1-1A & $\mathbf{a}$ & lys 2 ura 3 bo::LYS2 spr3::UR $A 3$ & Fares et al. (1996) \\
\hline CDV48 & $a / \alpha$ & $\begin{array}{l}\text { bis3/HIS3 leu2/LEU2 lys } 2 / \text { lys } 2 \text { trp1/TRP1 } \\
\text { ura3/ura3 bo::LYS2/HO } \\
\text { spr284::TRP1/SPR28 spr3::URA3/SPR3 }\end{array}$ & CDV45-3D $\times$ HF1-1A \\
\hline EGY48 & $\mathbf{a}$ & bis $3 \operatorname{trp} 1$ ura 3 LEU2::pLexAop6-LEU2 & Zervos et al. (1993) \\
\hline AMP109 & $a / \alpha$ & $\begin{array}{l}\text { leu2:: hisG/leu2:: bisG lys } 2 / \text { lys } 2 \\
\operatorname{trp} 1:: \text { bisG/trp } 1:: \text { bisG ura3/ura3 } \\
\text { bo::LYS2/bo::LYS } 2\end{array}$ & Bowdish et al. (1995) \\
\hline
\end{tabular}

* CDV45-3A, CDV45-3B, CDV45-3C and CDV45-3D are segregants from the same tetrad.

f Constructed by mating segregants from CDV45 as specified in the text.

(CDC3, CDC10, CDC11 and CDC12) or genomic DNA (SPR3 and $S P R 28)$ as templates. Appropriate restriction sites were introduced with the primers. Sequences that encode either the amino-terminal portions $(-N)$ of $C d c 3 p$ (amino acids 1-422), Cdc11p (amino acids 1-346), Cdc12p (amino acids 1-336), Spr3p (amino acids 1-370) or Spr28p (amino acids 1-383), or the carboxy-terminal portions $(-C$ ) of $C d c 3 p$ (amino acids 421-520), Cdc11p (amino acids 342-415), Cdc12p (amino acids 325-407), Spr3p (amino acids 363-512) or Spr28p (amino acids 378-423) were also amplified by PCR. The PCR products were cloned at the EcoRI site (CDC3), the XboI site (CDC10, CDC11, $C D C 11-N$ and $C D C 12$ ), or at the EcoRI-XboI sites (all other constructs) of pEG202 and pJG4-5. The constructs cloned at the EcoRI or EcoRI-XboI sites of pEG202 contain two additional amino acids (EF), and the ones cloned at the $X b o \mathrm{I}$ site contain 13 additional amino acids (EFPGIRRPWRPLE) between the LexA DBD and the first amino acid of the fused protein. All constructs but those encoding the amino-terminal sequences have the original stop codons of the fused genes. The constructs with the amino-terminal sequences have a stop codon immediately downstream of the polylinker.

Strain EGY48 (Table 1) containing the LexAop-lac $Z$ reporter plasmid pSH18-34 (Gyuris et al., 1993) was cotransformed with a pEG202 derivative expressing a LexA-DBD fusion protein and with pJG4-5 or a pJG4-5 derivative expressing an ADfusion protein. $\beta$-Galactosidase activities were measured in cultures of several independent transformants grown for $16 \mathrm{~h}$ at $30{ }^{\circ} \mathrm{C}$ in minimal medium containing $0.1 \mathrm{mg}$ leucine $\mathrm{ml}^{-1}, 2 \%$ $(\mathrm{w} / \mathrm{v})$ galactose and $1 \%(\mathrm{w} / \mathrm{v})$ raffinose.

RNA and protein analyses. The preparation of RNA and of the RNA blot (generously provided by A. Mitchell, Columbia University, New York, USA), and a control verifying that the lanes contain equivalent amounts of RNA, have been described previously (Bowdish et al., 1995). ${ }^{32}$ P-labelled probes were prepared using the Random Primed DNA Labeling kit (Boehringer Mannheim) according to the manufacturer's in- structions. For SPR 28, the fragment encoding the aminoterminal 383 amino acids (as used in the two-hybrid constructs; see above) was labelled. For CDC12, a PCR product corresponding to the complete ORF was labelled. Hybridizations were performed at $68^{\circ} \mathrm{C}$ in Express Hyb Hybridization Solution (Clontech) according to the manufacturer's instructions.

Proteins were extracted from $S$. cerevisiae by pelleting the cells from $10 \mathrm{ml}$ of a sporulating culture $\left(2 \times 10^{7}\right.$ cells $\left.\mathrm{ml}^{-1}\right)$ and resuspending the cells in $240 \mu 12.5 \times$ Laemmli buffer (Laemmli, 1970). The cells were sonicated for $5 \mathrm{~s}$ and boiled for $10 \mathrm{~min}$. Samples $(30 \mu \mathrm{l})$ were run on an SDS-polyacrylamide gel $(8 \%$, $\mathrm{w} / \mathrm{v}$, acrylamide) and transferred electrophoretically to nitrocellulose membranes as described previously (Ford \& Pringle, 1991). For immunodetection of the Spr28p-GFP fusion protein, the membrane was incubated with anti-GFP antibodies (Clontech), which were then visualized using the ECL Western blotting method (Amersham) according to the manufacturer's instructions.

Amino acid sequence comparisons. The University of Wisconsin Genetics Computer Group (GCG) programs were used to compile and analyse the sequence data. Alignments were performed using the GAP, PILEUP and PRETTY comparison programs.

Morphological observations. The overall morphologies of cells and asci were determined after growth for $4 \mathrm{~d}$ in liquid sporulation medium. Cultures were sonicated briefly and observed using either an oil-immersion $60 \times$ objective with differential-interference-contrast (DIC) optics or a $40 \times$ objective with phase-contrast optics. For visualization of the GFPfusion protein, cells were fixed in ice-cold $70 \%(\mathrm{v} / \mathrm{v})$ ethanol, washed once with water, resupended in mounting medium (Pringle et al., 1991) containing 0.05 $\mu \mathrm{g}$ bisBenzimide (Sigma) $\mathrm{ml}^{-1}$ and observed using a Nikon Microphot SA microscope with an IF380-490 FITC filter set. 


\section{RESULTS}

\section{Characterization of SPR28 and its product}

A search of the Genbank and SwissProt databases revealed a previously unidentified member of the septin gene family in $S$. cerevisiae. Its nucleotide sequence, located on chromosome IV, was deposited by B. Barrell \& M. A. Rajandream under the accession number Z48612 (ORF number YD9934.03c) as part of the yeast genome project.

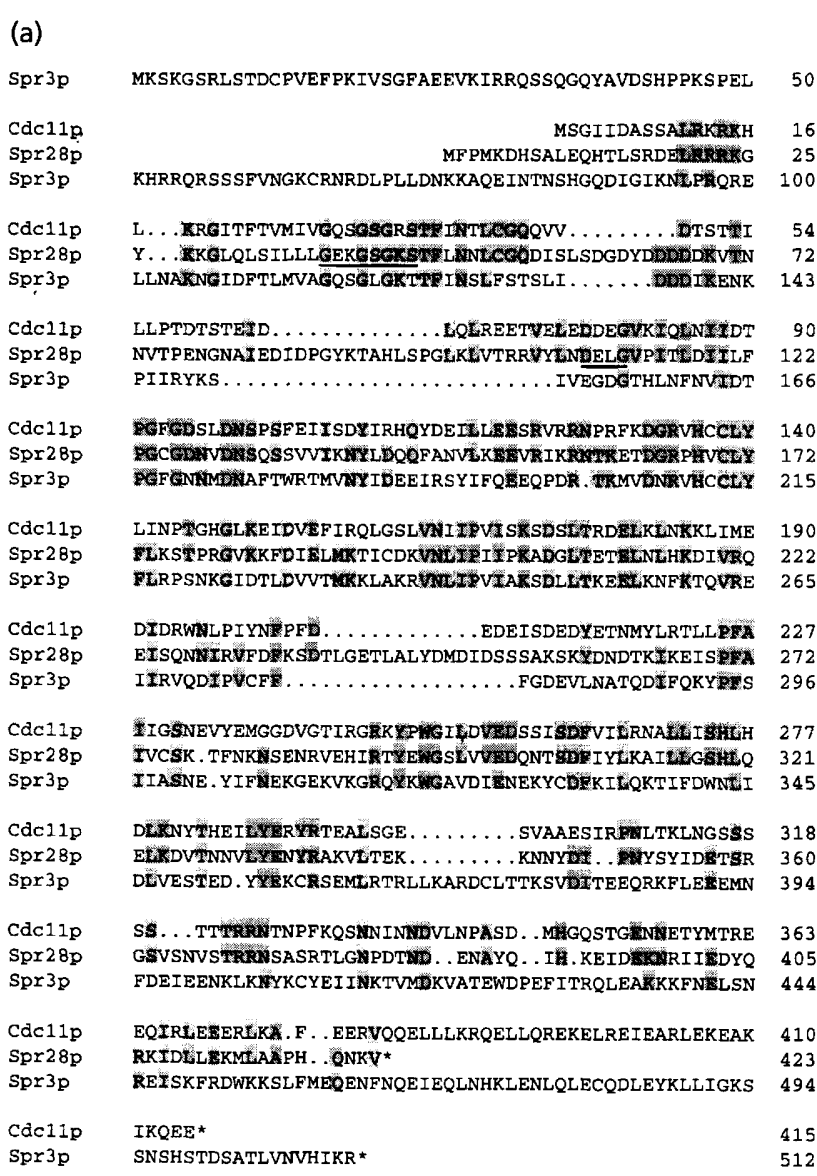

(b)

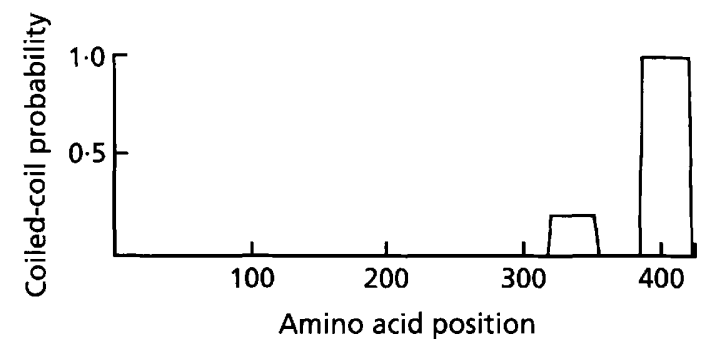

Fig. 1. (a) Sequence alignment of $S$. cerevisiae Spr $28 p$, Cdc11p and Spr3p (see Methods). Dots indicate gaps introduced to maximize sequence alignment; numbers indicate amino acid positions. Shading indicates amino acids that are the same in Spr28p and one or both of the other proteins. Motifs of the predicted nucleotide-binding site are underlined. (b) Probability of coiled-coil formation for Spr28p as predicted by the empirical program of Lupas et al. (1991) using a window size of 28 residues. (a)

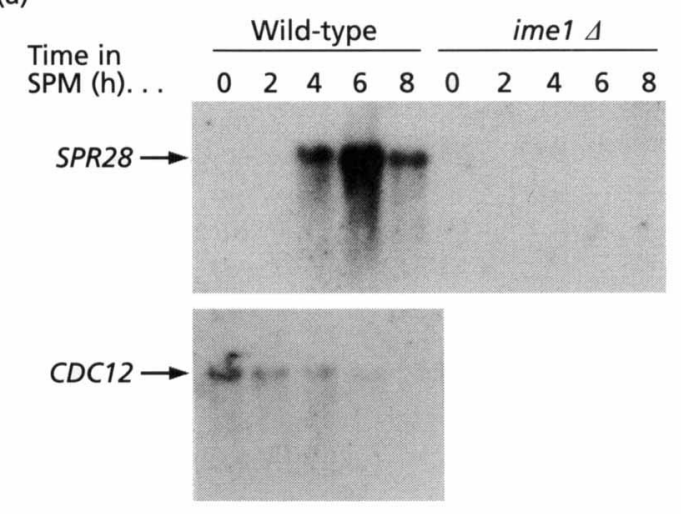

(b)

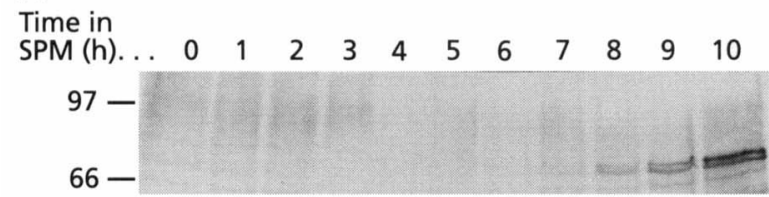

Fig. 2. (a) Accumulation of SPR28 mRNA and loss of $C D C 12$ mRNA in sporulating cells. RNA was prepared from cells growing exponentially in YPAC $(0 \mathrm{~h})$ and from cells harvested 2, 4,6 or $8 \mathrm{~h}$ after a shift to sporulation medium (SPM) (Bowdish et al., 1995). The Northern blot was probed with ${ }^{32} \mathrm{P}$-labelled SPR28 or CDC12 DNA as described in Methods. The strains used were AMP1179 (MATa/ $\alpha$, wild-type) and AMP258 $\times 1184$ (MATa/ $\alpha$ ime1 1/lime1 14) (see Bowdish et al., 1995). (b) Immunoblot analysis of Spr28p-GFP fusion protein expression. Cultures were grown to mid-exponential phase in YPAC and transferred to sporulation medium. Proteins were extracted from the YPACgrown cells $(0 \mathrm{~h})$ and from cells removed at hourly intervals after transfer to sporulation medium. The proteins were separated by SDS-PAGE, blotted and probed with anti-GFP antibodies as described in Methods. The predicted molecular mass of the Spr28p-GFP fusion protein $(76.9 \mathrm{kDa})$ is in good agreement with the estimated sizes $(\sim 74$ and $\sim 77 \mathrm{kDa}$ ) of the two polypeptides induced between 7 and $10 \mathrm{~h}$ after the transfer to sporulation medium. The smaller of these two polypeptides may be a degradation product of the larger. The mobilities of the flanking molecular size markers (97 and $66 \mathrm{kDa}$ ) are indicated.

Analysis of the sequence showed an ORF of 1269 nucleotides predicting a protein of 423 amino acids $(48.2 \mathrm{kDa})$. Based on (i) its SPorulation-Regulated transcription (see below) and (ii) the previous identification of 27 other SPR genes (Clancy et al., 1983; Holaway et al., 1987), we designated this gene SPR28. The SPR28 ORF is flanked by several in-frame stop codons.

The predicted Spr28p sequence shows clearly that it is a sixth member of the $S$. cerevisiae septin family (Fig. 1a); sequence identities range from $27 \%$ (with $\mathrm{Cdc} 3 \mathrm{p}$ ) to $35 \%$ (with Cdc11p) over the full length of the shorter protein in each case. Spr28p is also related to septins from other organisms (sequence identities ranging from $27 \%$ to $34 \%$ ) but does not have a particularly close homologue among the known proteins. Like all other known members of the septin family, Spr28p has amino acid motifs that are conserved among nucleotide-binding 
Table 2. Timing of meiosis in strain AMP109

The percentages of cells with one, two or four distinct nuclear DNA masses are shown at various time points after transfer to sporulation medium (SPM). At least 400 individual cells were analysed for each time point.

\begin{tabular}{|cccc|}
\hline $\begin{array}{c}\text { Time in } \\
\text { SPM (h) }\end{array}$ & \multicolumn{3}{c|}{ Percentage of cells with: } \\
\cline { 2 - 4 } & $\begin{array}{c}\text { 1 DNA } \\
\text { mass }\end{array}$ & $\begin{array}{l}\text { 2 DNA } \\
\text { masses }\end{array}$ & $\begin{array}{c}\text { 4 DNA } \\
\text { masses }\end{array}$ \\
\hline 1 & 100 & 0 & 0 \\
2 & 100 & 0 & 0 \\
3 & 100 & 0 & 0 \\
4 & 100 & 0 & 0 \\
5 & 100 & 0 & 0 \\
6 & 99 & 1 & 0 \\
7 & 91 & 9 & 0 \\
8 & 75 & 15 & 10 \\
9 & 51 & 19 & 22 \\
10 & 44 & 12 & 44 \\
\hline
\end{tabular}

proteins (Fig. 1a) (Saraste et al., 1990; Bourne et al., 1991). In addition, Spr28p, like most (but not all) of the other septins, contains a region near its carboxy-terminus (amino acids 385-417) that is predicted ( $>98 \%$ probability) to form a coiled-coil (Lupas et al., 1991) (Fig. 1b).

\section{Sporulation-specific expression of SPR28}

To determine if SPR28 is expressed in vegetative cells, sporulating cells, or both, a filter containing total RNA isolated from cells at various times after a shift to sporulation medium was hybridized with labelled SPR 28 DNA. No SPR 28 transcripts were detected in vegetatively growing wild-type cells (Fig. $2 \mathrm{a}, 0 \mathrm{~h}$ ). However, the SPR 28 transcript levels increased dramatically after $4 \mathrm{~h}$ in sporulation medium and peaked after $6 \mathrm{~h}$ (Fig. 2a). Thus, given the time course of sporulation in this and related strains (Table 2; Bowdish et al., 1995), the SPR28 transcript was first detectable at the beginning of meiosis I and was maximal just prior to meiosis II. In contrast, transcript levels for the vegetatively expressed septin gene $C D C 12$ declined progressively as sporulation proceeded (Fig. 2a).

Because deletion of IME1 eliminates expression of almost all sporulation-specific genes and blocks all tested events in meiosis and sporulation (Mitchell, 1994), we also examined the expression pattern of $S P R 28$ in an ime 14/ime1A strain. No SPR 28 transcripts were detected in either vegetatively growing or sporulating cells (Fig. $2 \mathrm{a}$ ), indicating that SPR 28 expression requires $I M E 1$, as expected.

\section{Expression and localization of Spr28p in sporulating cells}

To examine the timing of Spr28p expression and its intracellular localization, we examined wild-type cells (AMP109; Table 1) that expressed an Spr28p-GFP fusion protein under the control of the SPR 28 promoter. Consistent with the results of the RNA analyses, no Spr28p-GFP was detected by immunoblotting of extracts from vegetatively growing cells (Fig. 2b, $0 \mathrm{~h}$ ), but Spr28p-GFP was present in increasing amounts in cells incubated for $7-10 \mathrm{~h}$ in sporulation medium (Fig. 2b). Initial detection of the Spr28p-GFP fusion protein coincided with the first appearance of cells that had completed meiosis I (cells with two DNA masses; Table 2). This observed timing of Spr28p-GFP expression in sporulating cells is very similar to that of Spr3p under the same conditions (Fares et al., 1996).

To determine the intracellular localization of Spr28pGFP, we examined cells that had been in sporulation medium for $10 \mathrm{~h}$. Consistent with the previously reported localizations of Spr3p, Cdc3p and Cdc11p (Fares et al., 1996), the Spr28p-GFP fusion protein localized to ringlike structures around each of the four nuclear lobes at the onset of and during meiosis II (Fig. 3a, d). At later stages, Spr28p-GFP appeared to be found over the entire
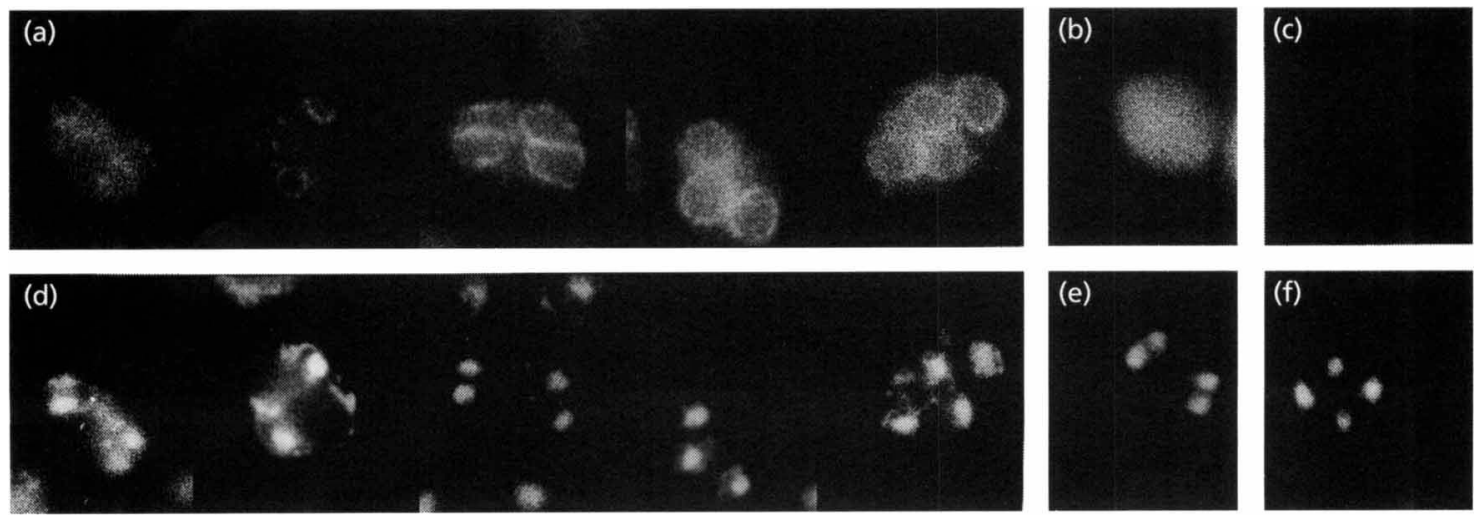

Fig. 3. Localization of Spr28p-GFP in sporulating cells. Strain AMP109 carrying YEplac181-SPR28-GFP (a, d), YEplac181-GFP $(b, e)$ or YEplac181 (c, f) was pregrown on SD-Leu medium, grown to mid-exponential phase in YPAC and incubated for $10 \mathrm{~h}$ in sporulation medium. The fluorescence of cells expressing Spr28p-GFP (a), GFP (b) or no additional protein (c) was visualized as described in Methods. (d, e, f) DNA staining of the cells shown in a, b and c, respectively. 
Table 3. Two-hybrid interactions of Spr28p with itself and other septins

Possible interactions between $\operatorname{Spr} 28 \mathrm{p}$ and other $S$. cerevisiae septins were evaluated using the twohybrid system as described in Methods. Numbers represent mean $\beta$-galactosidase activities (in Miller units) from three different transformants for each pair of plasmids. The characters ' $N$ ' and ' $C$ ' designate sequences encoding the amino- or carboxy-terminal portions, respectively, of the various septins as specified in Methods. pJG4-5 indicates the AD vector with no septin insert. Values that were above 100 units and at least sixfold higher than the corresponding control (pJG4-5 without insert) are shown in bold.

\begin{tabular}{|c|c|c|c|c|c|c|}
\hline \multirow[t]{2}{*}{$A D$ fusion } & \multicolumn{6}{|c|}{ DBD fusion } \\
\hline & SPR 28 & $S P R 28-N$ & SPR28-C & SPR3 & SPR3-N & SPR3.C \\
\hline SPR 28 & 6 & 14 & 39 & 51 & 914 & 7 \\
\hline$S P R 28-N$ & 1278 & 130 & 20 & 39 & 374 & 6 \\
\hline$S P R 28-C$ & 90 & 37 & 44 & 21 & 16 & 4 \\
\hline SPR3 & 207 & 171 & 6 & 14 & 8 & 5 \\
\hline$S P R 3-N$ & 1841 & 1840 & 25 & 6 & 14 & 11 \\
\hline$S P R 3-C$ & 2 & 7 & 16 & 2 & 9 & 7 \\
\hline$C D C 3$ & 150 & 9 & 13 & 12 & 8 & 15 \\
\hline$C D C 3-N$ & 9 & 12 & 19 & 6 & 11 & 8 \\
\hline$C D C 3-C$ & 6 & 12 & 35 & 5 & 5 & 18 \\
\hline$C D C 10$ & 10 & 8 & 24 & 25 & 11 & 38 \\
\hline$C D C 11$ & 3402 & 3927 & 39 & 3 & 16 & 3 \\
\hline$C D C 11-N$ & 3957 & 3776 & 13 & 3 & 13 & 7 \\
\hline$C D C 11-C$ & 53 & 69 & 48 & 3 & 6 & 7 \\
\hline$C D C 12$ & 31 & 45 & 32 & 4 & 16 & 10 \\
\hline$C D C 12-N$ & 43 & 45 & 30 & 5 & 6 & 2 \\
\hline$C D C 12-C$ & 8 & 17 & 14 & 6 & 11 & 38 \\
\hline pJG4-5 & 18 & 10 & 31 & 21 & 10 & 4 \\
\hline
\end{tabular}

prospore wall (Fig. 3a, d and data not shown). Cells expressing GFP alone under control of the SPR28 promoter showed only dispersed fluorescence over the entire cell at comparable stages of sporulation (Fig. 3b, e). The fluorescence signal was completely absent in cells carrying only an empty control vector (Fig. 3c, f). 'Thus, Spr28p, like the other septins examined to date (Fares et al., 1996), appears to be concentrated initially at the leading edges of the developing prospore wall and later is found over this entire structure.

\section{Two-hybrid analysis of Spr28p interactions}

A variety of data suggests that the septins interact intimately with each other (Longtine et al., 1996). To investigate the possible interactions of Spr28p with the other septins, directed two-hybrid analysis (Fields \& Sternglanz, 1994) was performed. Interactions were detected between Spr28p and itself, Spr3p, Cdc3p and Cdc11p (Table 3). Thus, Spr28p appears to interact directly with itself and with some, but not all, of the other septins that are expressed in sporulating cells. [Based on its high mRNA levels (Kaback \& Feldberg, 1985), Cdc10p is also expected to be abundant in sporulating cells. The levels of Cdc12p have not been examined].

Interestingly, the interaction with Spr28p was the only interaction detected for Spr3p (see Discussion). Also of interest was the finding that the interactions of Spr28p with itself, Spr3p and Cdc11p all appeared to be independent of the carboxy-terminal coiled-coil regions, as the interactions were observed when one or both of the interacting proteins were truncated upstream of this region (Table 3 ).

\section{Effects of SPR28 deletion}

To determine the consequences of a loss of Spr28p, we replaced the complete SPR 28 coding region with TRP1 (Fig. 4a; see Methods). A transformant carrying the deletion (CDV45) was identified by PCR and confirmed by Southern blotting (Fig. 4b). Homozygous spr284/spr284 diploids (CDV46-1 to CDV46-6; Table 1) and related homozygous wild-type diploids (CDV47-1 to CDV47-6) were constructed by inducing sporulation in CDV45 and mating appropriate pairs of segregants. Consistent with the apparent lack of SPR 28 expression in vegetative cells, spr284 haploids and homozygous mutant diploids showed no obvious change in growth rate at 20 , 30 or $37^{\circ} \mathrm{C}$, and no morphological abnormalities or defects in budding pattern, when compared to wild-type sister segregants or homozygous wild-type diploids. More surprisingly, when the efficiencies of sporulation of the homozygous spr284/spr284 and related wild-type diploids were compared, there was little or no difference. 
(a)

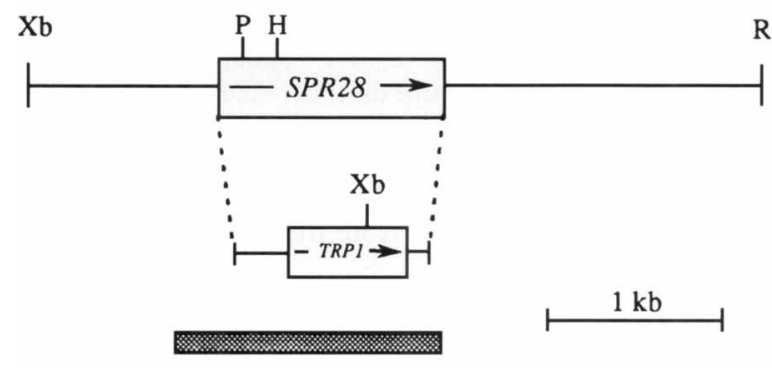

(b)

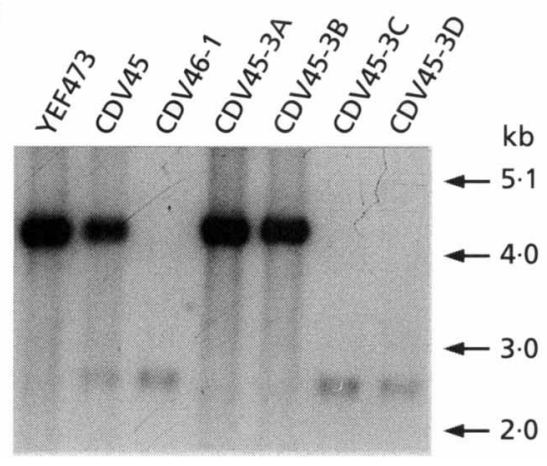

Fig. 4. (a) Physical map of the SPR28 region and structure of the spr284::TRP1 deletion. All cleavage sites for EcoRI (R), HindIII (H), Pstl (P) and Xbal (Xb) are shown. The location and direction of transcription of the SPR28 coding region are shown along with the structure of the deletion allele containing TRP1 (direction of transcription indicated by the arrow) and TRP1flanking regions (see Methods). The shaded bar represents the DNA fragment used as a probe for Southern blot analysis. (b) Southern blot analysis of strains with and without the spr284::TRP1 deletion. YEF473 is the parental diploid strain; CDV45 is the heterozygous diploid obtained by transformation of YEF473 with the spr284::TRP1 construct; CDV45-3A to CDV45-3D are the four segregants from one tetrad of CDV45. and CDV46-1 is the homozygous spr284::TRP1/spr284::TRP1 diploid formed by mating CDV45-3C with CDV45-3D. Genomic DNAs were digested with $X$ bal and EcoRI, and DNA blots were hybridized with a PCR-generated DNA fragment containing the SPR28 coding region and upstream sequences (see a). The mobilities of molecular size markers are indicated. Bands of the predicted sizes $(4.2 \mathrm{~kb}$ for wild-type and $2.5 \mathrm{~kb}$ for spr284::TRP1 strains) were observed in the expected lanes.

After $4 \mathrm{~d}$ in sporulation medium, the six CDV46 series strains displayed 12-17\% (mean 15\%) 4-spored asci (counts of 400 cells per strain), compared to $14-22 \%$ (mean 17\%) for the six CDV47 series strains.

Previous work had shown that deletion of either SPR3 or CDC10 reduced sporulation efficiency in some genetic backgrounds (Fares et al., 1996). The possibility of redundancy in function between Spr3p and Cdc10p proved difficult to test because an $s p r 3 / s p r 3 c d c 10 / c d c 10$ double mutant diploid could not be constructed. We thought that an spr3/spr3 spr28/spr28 double mutant might be easier to construct (because neither gene appears to play a role in vegetative growth) and might display a more severe sporulation block than either of the single mutants. Thus, we constructed six homozygous

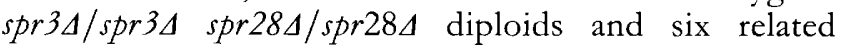
homozygous wild-type diploids by inducing sporulation in CDV48 (a double heterozygote; Table 1) and mating appropriate pairs of segregants. As expected, vegetatively growing spr34 spr284 haploids as well as homozygous mutant diploids showed no obvious change in growth rate at 20 or $30^{\circ} \mathrm{C}$ or morphological abnormalities when compared to wild-type sister segregants or homozygous wild-type diploids. Surprisingly, however, we also found little or no difference in sporulation efficiency when the

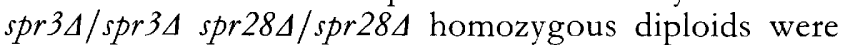
compared to related wild-type diploids. After $4 \mathrm{~d}$ in sporulation medium, the six spr3A/spr34 spr284/spr284 strains displayed 24-62\% (mean 42\%) 4-spored asci (counts of 200 cells per strain), compared to $52-76 \%$ (mean 63\%) for the six homozygous wild-type strains.

\section{DISCUSSION}

SPR28, a gene identified during the yeast genome project (B. Barrell \& M. A. Rajandream, unpublished results), encodes a sixth member of the $S$. cerevisiae septin family. Recently, the existence of a seventh (and final) $S$. cerevisiae septin gene has been revealed by the completion of the genome project. The expression and function of this gene and its product are currently under investigation.

Spr28p is $\sim 30 \%$ identical in amino acid sequence to the other known septins and does not have a particularly close homologue among them; in particular, there is no obvious special similarity between Spr28p and Spr3p or the Schizosaccharomyces pombe septin(s) that appear to be expressed specifically in sporulating cells (Fig. 1; O. AlAwar, H. B. Kim \& J. R. Pringle, unpublished results). Like all of the other known septins, Spr28p contains a putative nucleotide-binding site that might be involved in the control of septin assembly and/or function. However, the role of this site has yet to be elucidated in any septin. In addition, like all but a few of the other known septins (Longtine et al., 1996), Spr28p contains a predicted coiledcoil domain near its carboxy terminus. This domain is likely to be involved in interactions among the septins or between the septins and other proteins. Interestingly, the observed two-hybrid interactions between Spr28p and itself, Spr $3 p$ and Cdc11p were not mediated by the coiledcoil domains but rather by the amino-terminal portions of all three proteins. This finding does not necessarily exclude a tole for the coiled-coil domains in inter-septin interactions. However, if the inter-septin interactions are indeed mediated solely by their amino termini, the coiledcoil domains might serve as anchors for other proteins being recruited to the site of septin assembly.

The localization of the Spr28p-GFP fusion protein during meiosis II and spore formation was very similar to that observed previously for Spr3p, Cdc3p and Cdc11p (Fares et al., 1996), suggesting a close association of these (and perhaps other) septins with each other and with the developing prospore wall. Indeed, two-hybrid analyses suggested that Spr28p interacts directly with itself, Spr3p, 
Cdc $3 p$ and Cdc11p. Interestingly, the strong interaction with Spr28p was the only interaction detected for Spr3p, suggesting that Spr28p may play a special role in recruiting Spr3p into the putative septin complex at the prospore wall. In previous studies, the localization of $\mathrm{Cdc} 3 \mathrm{p}$ and $\mathrm{Cdc11}$ p to the prospore wall appeared to be partly, but not completely, dependent on the presence of Spr3p. Further work will be necessary to elucidate the full set of interactions necessary for proper localization and assembly of the septins in sporulating cells.

The apparent localization of the septins to the leading edge of the early prospore wall (Fig. 4; Fares et al., 1996) suggests that these proteins may be involved in the extension of this structure, but we have as yet no strong evidence for such a role. Alternatively (or in addition), the septins may be involved in the formation of the spore wall, a process that appears to begin only after encapsulation of the spore nucleus and cytoplasm are complete or nearly so (Moens, 1971; Beckett et al., 1973; Byers, 1981 ; Fares et al., 1996). In this context, it should be noted that the formation of the spore wall chitosan layer depends on chitin synthase III (Briza et al., 1988; Pammer et al., 1992; Bulawa, 1993), the same enzyme that produces the chitin ring at the base of the bud in vegetative cells (Bulawa, 1993). The vegetatively expressed septins appear to be involved in the localization of chitin synthase III activity through interactions that involve the Chs $4 p$ (Csd4p) and Bni4p proteins (D. DeMarini, H. Fares \& J. R. Pringle, unpublished results). Chs4p has a homologue, Shc1p, that is expressed specifically in sporulating cells (Bulawa, 1993). Thus, the septins may be involved in the organization of spore wall chitosan formation through interaction with Shc1p and Bni4p or a sporulation-specific homologue.

If the septins play an important role in extension of the prospore wall and/or in spore wall formation, why have the septin mutations examined had such modest (or even undetectable) effects on spore formation (Simchen, 1974; Kao et al., 1989; Fares et al., 1996; this study)? The failure to see effects with temperature-sensitive alleles of $C D C 3$, $C D C 10$ and $C D C 11$ (Simchen, 1974) might have resulted from the need to do the tests of sporulation at a temperature that may not have been fully restrictive for the alleles used. However, deletions of CDC10, SPR 3 and SPR 28 also produce only modest effects on sporulation efficiency. The answer seems likely to lie, at least in part, in functional redundancy among the septins, a phenomenon for which evidence also exists in vegetative cells (Longtine et al., 1996). However, we have as yet no strong evidence for this hypothesis. We were unable to construct stable $c d c 10 \Delta / c d c 10 \Delta s p r 3 \Delta / s p r 3 \Delta$ diploids (Fares et al., 1996), and results with spr34/spr34 spr284/spr284 diploids, although variable, showed no consistent, strong block of spore formation (this study). Thus, remarkably, neither of the known sporulation-specific septins is strictly required for sporulation. Further studies will be required to unravel the possible redundancies in function among the septins and thus (perhaps) to allow decisive studies of the septin role(s) in a strain with a strong defect in sporulation.

\section{ACKNOWLEDGEMENTS}

We thank Aaron Mitchell for advice and for the Northern blot used in the experiments of Fig. 2, and we thank the members of our laboratory for helpful discussions. This work has been supported by NIH Grant GM31006 and by funds from the RJEG Trust. C.D.V. was supported by fellowships from the L. \& Th. LaRoche Stiftung and the Ciba-Geigy-JubilaeumsStiftung, and by a travel grant from the Theodor EngelmannStiftung.

\section{REFERENCES}

Adams, A. E. M. (1984). Cellular morphogenesis in the yeast Saccharomyces cerevisiae. $\mathrm{PhD}$ thesis, The University of Michigan.

Adams, A. E. M. \& Pringle, J. R. (1984). Relationship of actin and tubulin distribution to bud growth in wild-type and morphogenetic-mutant Saccharomyces cerevisiae. J Cell Biol 98, 934-945.

Baudin, A., Ozier-Kalogeropoulos, O., Denouel, A., Lacroute, F. \& Cullin, C. (1993). A simple and efficient method for direct gene deletion in Saccharomyces cerevisiae. Nucleic Acids Res 21, 3329-3330.

Beckett, A., Illingworth, R. F. \& Rose, A. H. (1973). Ascospore wall development in Saccharomyces cerevisiae. J Bacteriol 113, 1054-1057.

Bi, E. \& Pringle, J. R. (1996). ZDS1 and ZDS2, genes whose products may regulate Cdc42p in Saccharomyces cerevisiae. Mol Cell Biol (in press).

Bourne, H. R., Sanders, D. A. \& McCormick, F. (1991). The GTPase superfamily: conserved structure and molecular mechanism. Nature 349, 117127.

Bowdish, K. S., Yuan, H. E. \& Mitchell, A.P. (1995). Positive control of yeast genes by the negative regulator UME6. Mol Cell Biol 15, 2955-2961.

Briza, P., Ellinger, A., Winkler, G. \& Breitenbach, M. (1988). Chemical composition of the yeast ascospore wall. The second outer layer consists of chitosan. J Biol Chem 263, 11569-11574.

Bulawa, C. E. (1993). Genetics and molecular biology of chitin synthesis in fungi. Annu Rev Microbiol 47, 505-534.

Byers, B. (1981). Cytology of the yeast life cycle. In The Molecular Biology of the Yeast Saccbaromyces: Life Cycle and Inberitance, pp. 59-96. Edited by J. N. Strathern, E. W. Jones \& J. R. Broach. Cold Spring Harbor, NY: Cold Spring Harbor Laboratory.

Byers, B. \& Goetsch, L. (1976). A highly ordered ring of membraneassociated filaments in budding yeast. J Cell Biol 69, 717-721.

Clancy, M. J., Buten-Magee, B., Straight, D. J., Kennedy, A. L., Partridge, R. M. \& Magee, P. T. (1983). Isolation of genes expressed preferentially during sporulation in the yeast Saccharomyces cerevisiae. Proc Natl Acad Sci US A 80, 3000-3004.

Davis, R. W., Botstein, D. \& Roth, J. R. (1980). Advanced Bacterial Genetics: a Manual for Genetic Engineering. Cold Spring Harbor, NY: Cold Spring Harbor Laboratory.

Esposito, R. E. \& Klapholz, S. (1981). Meiosis and ascospore development. In The Molecular Biology of the Yeast Saccharomyces: Life Cycle and Inberitance, pp. 211-287. Edited by J. N. Strathern, E. W. Jones \& J. R. Broach. Cold Spring Harbor, NY: Cold Spring Harbor Laboratory.

Fares, H., Goetsch, L. \& Pringle, J. R. (1996). Identification of a developmentally regulated septin and involvement of the septins in spore formation in Saccharomyces cerevisiae. J Cell Biol 132, 399-411.

Fields, S. \& Sternglanz, R. (1994). The two-hybrid system : an assay for protein-protein interactions. Trends Genet 10, 286-292.

Ford, S. K. \& Pringle, J. R. (1991). Cellular morphogenesis in the Saccharomyces cerevisiae cell cycle: localization of the CDC11 gene 
product and the timing of events at the budding site. Dev Genet 12, 281-292.

Gietz, R. D. \& Sugino, A. (1988). New yeast-Escherichia coli shuttle vectors with in vitro mutagenized yeast genes lacking six-base pair restriction sites. Gene 74, 527-534.

Gietz, D., St. Jean, A., Woods, R. A. \& Schiestl, R. H. (1992). Improved method for high efficiency transformation of intact yeast cells. Nucleic Acids Res 20, 1425.

Guth, E., Hashimoto, T. \& Conti, S. F. (1972). Morphogenesis of ascospores in Saccharomyces cerevisiae. J Bacteriol 109, 869-880.

Guthrie, C. \& Fink, G. R. (editors) (1991). Guide to yeast genetics and molecular biology. Methods Enzymol 194.

Gyuris, J., Golemis, E., Chertkov, H. \& Brent, R. (1993). Cdi1, a human $\mathrm{G} 1$ and $S$ phase protein phosphatase that associates with Cdk2. Cell 75, 791-803.

Haarer, B. K. \& Pringle, J. R. (1987). Immunofluorescence localization of the Saccharomyces cerevisiae CDC12 gene product to the vicinity of the $10-\mathrm{nm}$ filaments in the mother-bud neck. Mol Cell Biol 7, 3678-3687.

Hartwell, L. H. (1971). Genetic control of the cell division cycle in yeast. IV. Genes controlling bud emergence and cytokinesis. Exp Cell Res 69, 265-276.

Holaway, B. L., Kao, G., Finn, M. C. \& Clancy, M. J. (1987). Transcriptional regulation of sporulation genes in yeast. Mol Gen Genet 210, 449-459.

Kaback, D. B. \& Feldberg, L. R. (1985). Saccharomyces cerevisiae exhibits a sporulation-specific temporal pattern of transcript accumulation. Mol Cell Biol 5, 751-761.

Kao, G., Mannix, D. G., Holaway, B. L., Finn, M. C., Bonny, A. E. \& Clancy, M. J. (1989). Dependence of inessential late gene expression on early meiotic events in Saccharomyces cerevisiae. Mol Gen Genet 215, $490-500$.

Kim, H. B., Haarer, B. K. \& Pringle, J. R. (1991). Cellular morphogenesis in the Saccharomyces cerevisiae cell cycle: localization of the $C D C 3$ gene product and the timing of events at the budding site. J Cell Biol 112, 535-544.

Laemmli, U. K. (1970). Cleavage of structural proteins during the assembly of the head of bacteriophage T4. Nature 227, 680-685.

Lillie, S. H. \& Pringle, J. R. (1980). Reserve carbohydrate metabolism in Saccharomyces cerevisiae : responses to nutrient limitation. J Bacteriol 143, 1384-1394.

Longtine, M. S., DeMarini, D. J., Valencik, M. L., Al-Awar, O. S., Fares, H., De Virgilio, C. \& Pringle, J. R. (1996). The septins: roles in cytokinesis and other processes. Curr Opin Cell Biol 8, 106-119.

Lupas, A., Van Dyke, M. \& Stock, J. (1991). Predicting coiled coils from protein sequences. Science 252, 1162-1164.
Mitchell, A. P. (1994). Control of meiotic gene expression in Saccbaromyces cerevisiae. Microbiol Rev 58, 56-70.

Moens, P. B. (1971). Fine structure of ascospore development in the yeast Saccharomyces cerevisiae. Can J Microbiol 17, 507-510.

Moens, P. B. \& Rapport, E. (1971). Spindles, spindle plaques, and meiosis in the yeast Saccharomyces cerevisiae (Hansen). J Cell Biol 50, 344-361.

Ozsarac, N., Bhattacharyya, M., Dawes, I. W. \& Clancy, M. J. (1995). SPR 3 gene encodes a sporulation-specific homologue of the yeast $C D C 3 / 10 / 11 / 12$ family of bud neck microfilament genes and is regulated by ABFI. Gene 164, 157-162.

Pammer, M., Briza, P., Ellinger, A., Schuster, T., Stucka, R., Feldmann, H. \& Breitenbach, M. (1992). DIT101 (CSD2, CAL1), a cell cycle-regulated yeast gene required for synthesis of chitin in cell walls and chitosan in spore walls. Yeast 8, 1089-1099.

Pringle, J. R., Adams, A. E., Drubin, D. G. \& Haarer, B. K. (1991). Immunofluorescence methods for yeast. Methods Enzymol 194, 565-602.

Rose, M. D., Winston, F. \& Hieter, P. (1990). Methods in Yeast Genetics. Cold Spring Harbor, NY : Cold Spring Harbor Laboratory.

Sambrook, J., Fritsch, E. F. \& Maniatis, T. (1989). Molecular Cloning: a Laboratory Manual, 2nd edn. Cold Spring Harbor, NY: Cold Spring Harbor Laboratory.

Saraste, M., Sibbald, P. R. \& Wittinghofer, A. (1990). The P-loop: a common motif in ATP- and GTP-binding proteins. Trends Biochem Sci 15, 430-434.

Sikorski, R. S. \& Hieter, P. (1989). A system of shuttle vectors and yeast host strains designed for efficient manipulation of DNA in Saccharomyces cerevisiae. Genetics 122, 19-27.

Simchen, G. (1974). Are mitotic functions required in meiosis? Genetics 76, 745-753.

Slater, M. L., Bowers, B. \& Cabib, E. (1985). Formation of septumlike structures at locations remote from the budding sites in cytokinesis-defective mutants of Saccharomyces cerevisiae. J Bacteriol 162, 763-767.

Sterner, R., Dahm, A., Darimont, B., Ivens, A., Liebl, W. \& Kirschner, K. (1995). $(\beta \alpha)_{8}$-barrel proteins of tryptophan biosynthesis in the hyperthermophile Thermotoga maritima. EMBO J 14, 4395-4402.

Zervos, A. S., Gyuris, J. \& Brent, R. (1993). Mxi1, a protein that specifically interacts with Max to bind Myc-Max recognition sites. Cell 72, 223-232.

Received 25 April 1996; accepted 24 June 1996 